\section{“ELE MESMO CONTOU ISSO": NÉLIO NAJA, A PRODUÇÃO DE UM MITO}

\author{
"HE TOLD IT HIMSELF”: NÉLIO NAJA, THE PRODUCTION OF A MYTH \\ “LO CONTÓ ÉL MISMO”: NÉLIO NAJA, LA PRODUCCIÓN DE UN MITO.
}

Ivo Lopes Müller Júnior*, André Mendes Capraro*
Palavras chave:

Memória.

Identificação

Social.

Entrevista.

Keywords:

Memory.

Social

Identification.

Interview.

Palabras clave:

Memoria.

Identificación

social.

Entrevista.
Resumo: O presente estudo objetiva descontruir o discurso apresentado por Nélio Naja e amplamente aceito no meio do Muay Thai a respeito de como teria conhecido a modalidade. Para tanto, as seguintes questões foram elaboradas: onde Nélio Naja conheceu o Muay Thai? Como foi produzido o mito Nélio Naja? Na tentativa de responder a tais questionamentos, recorreu-se à história oral híbrida como método de investigação. Ao utilizar os conceitos de memória coletiva e mito, foram encontrados indícios de que a série de desenho animado Sawamu o inspirou a desenvolver a modalidade. A partir da socialização com seus alunos, ele inculcou algumas ideias a respeito de como tinha conhecido a modalidade, sendo repassado de aluno para aluno e cristalizando sua versão histórica a respeito de como conheceu o Muay Thai.

Abstract: This study aims to deconstruct Nélio Naja's discourse, which is widely accepted in Muay Thai, about how he knew the sport. The following questions were asked: Where did Nélio Naja knew Muay Thai? How was the Nélio Naja myth produced? To answer them, hybrid oral history was used as a method of investigation. Through the concepts of collective memory and myth, evidence showed that the Sawamu cartoon series inspired him to develop the sport. By socializing with his students, he instilled some ideas about how he would have known the sport, which were passed on from student to student and crystallized his historical version about how he got to know Muay Thai.

Resumen: Este estudio tiene como objetivo deconstruir el discurso presentado por Nélio Naja y ampliamente aceptado en el ámbito del Muay Thai sobre cómo habría conocido ese deporte. Para ello, se elaboraron las siguientes preguntas: ¿Dónde conoció Nélio Naja el Muay Thai? ¿Cómo fue producido el mito de Nélio Naja? para intentar responder a tales preguntas, se utilizó la historia oral híbrida como método de investigación. Al usar los conceptos de memoria colectiva y mito, se encontraron indicios de que la serie de dibujos animados Sawamu lo inspiró a desarrollar esa modalidad deportiva. Al socializar con sus alumnos, les inculcó algunas ideas sobre cómo conoció el deporte, pasando de estudiante a estudiante y cristalizando su versión histórica sobre cómo llegó a conocer el Muay Thai.
*Universidade Federal do Paraná. Curitiba, PR, Brasil.

E-mail:

ivojunior11@yahoo.com.br; andrecapraro@onda.com.br

Recebido em: 27-12-2019 Aprovado em: $10-06-2020$ Publicado em: 28-06-2020 
Apesar de saber as três versões [não] deixamos isso para outra pauta" (PEDROSO, 2019).

\section{INTRODUÇÃO}

Pesquisas relacionadas à história, tradição e autenticidade - sobretudo aquelas relacionadas às artes marciais e esportes de combate, - são conflituosas, principalmente as de origens asiáticas. Estudos como os publicados por Peter Vail (1998; 2014), Bowman (2016), Lise, Capraro (2018), Tralci Filho (2016) e Prado (2014) são alguns exemplos de dissidências acadêmicas em relação a uma origem remota dessas modalidades. No entanto, mesmo apresentando narrativas dúbias, alguns livros e artigos acadêmicos enaltecem e ajudam a consolidar essas metanarrativas.

A história do surgimento do Muay Thai no Brasil é curiosa e mistura em um único enredo misticismo, fatalidade e apostas no futuro (CIDADE, 2007). A maioria dos mestres e grãos mestres do Muay Thai brasileiro apontam para Nélio Borges de Souza, mais conhecido pelos praticantes por Nélio Naja, como precursor da modalidade no país (PASSOS et al., 2014). Nélio era carioca, formado faixa preta de Taekwondo por Woo Jae Lee. No ano de 1976, Nélio Naja mudou-se para Curitiba e adaptou técnicas orientais para criar o Muay Thai brasileiro (RUDNICK, 2015). Num primeiro momento a modalidade foi difundida com o nome de Boxe Tailandês (ALVES; MARIANO, 2007).

Nélio nasceu no Rio de Janeiro no ano de 1952 e faleceu na cidade de Almirante Tamandaré no dia 12 de julho de 2018. Ele foi um dos primeiros faixas pretas de Taekwondo formados no Brasil. Treinou na cidade do Rio de Janeiro, no período entre os anos de 1972 a 1976.

Existem algumas versões a respeito de como ele conheceu o Muay Thai. A de maior destaque alega que ele teria conhecido o Muay Thai quando estava na aeronáutica, onde serviu como paraquedista. Naja, após realizar uma missão na Ásia, supostamente teria permanecido por dois anos em Bangkok, capital da Tailândia. Ao regressar introduziu o Muay Thai no Brasil, iniciando pelas cidades de Curitiba e posteriormente no Rio de Janeiro (RUDNICK, 2015). Em entrevista concedida a revista digital Primeiro Round ${ }^{1}$ no ano de 2010, Nélio confirma a versão que teria ido para a Tailândia na década de 1970, e teria permanecido lá por dois anos aprendendo as técnicas da modalidade.

Nesse sentido, o objetivo do presente trabalho é descontruir o discurso apresentado por Nélio Naja e amplamente aceito no meio do Muay Thai a respeito de como teria conhecido a modalidade. Para tanto, as seguintes questões foram elaboradas: Aonde Nélio Naja conheceu o Muay Thai? Como foi produzido o mito Nélio Naja?

$\mathrm{Na}$ tentativa de responder tais questionamentos, optou-se por utilizar os pressupostos da história oral híbrida como método de investigação. A história oral se pauta na interpretação de narrativas e da mutabilidade de sociedades e culturas, mediante a escuta dos envolvidos e do registro de suas memórias. Uma de suas consequências é o fato de não permitir muita contestação (THOMPSON; ZHOURI;

1 ENTREVISTA Nélio Naja. 6 maio 2010. Disponível em: https://www.youtube.com/watch?v=i6Gu45WGnHA . Acesso em: 5 maio 2019. 
LEITE PEREIRA, 2002). Na "[...] história oral híbrida preza-se o poder da 'conversa', contatos ou diálogos com outros documentos, sejam iconográficos ou escritos como: historiográficos, filosóficos ou literários" (MEIHY; HOLANDA, 2015, p. 129). Portanto, foram utilizados neste estudo, além das fontes orais, matérias dos jornais: Correio de Notícias (1988), Gazeta do Povo (2007, 2015); Globo Esporte (2016); livros como: Campbell (1949; 1990); Candau (2011); Lee (2019); Reis; Rodrigues (2018).

O trabalho do historiador oral engloba uma confirmação detalhada dos fatos quando possível em outros tipos de fonte, "[...] a fim que possamos distinguir entre narrativas factualmente confiáveis, que são a maioria e os casos significativos de mitos e erro criativo" (PORTELLI, 2016, p. 19). De acordo com Verena Alberti (2013, p.158),

[...] a relação de documentos com a história oral é bidirecional: enquanto se obtém, das fontes já existentes, material para a pesquisa e realização de entrevista, esta última tornar-se-ão novos documentos enriquecendo e muitas vezes, explicando aqueles aos quais se recorreu no início (ALBERTI, 2013, p. 158).

Vale ressaltar que "[...] toda fonte histórica derivada da percepção humana é subjetiva, mas apenas a fonte oral permite-nos desafiar essa subjetividade: descolar as camadas de memória, cavar fundo em suas sombras, na expectativa de atingir a verdade oculta" (THOMPSON, 1992 p.197). As fontes orais permitem que uma história seja narrada de variadas formas em função do contexto no qual é relatada (POLLAK, 1989). Para isso optou-se em realizar entrevistas temáticas.

Neste estudo² foram realizadas oito entrevistas durante o ano de 2019 (Quadro 1), por meio de um roteiro semiestruturado de perguntas abertas. Ressalta-se que todos os entrevistados assinaram o Termo de Consentimento Livre Esclarecido e concordaram em divulgar seus nomes. A duração média das entrevistas foi de $1 \mathrm{~h} 28$ e após realizar a transcrição receberam a devolutiva das entrevistas.

Quadro 1 - Entrevistados

\begin{tabular}{|l|l|l|l|l|}
\hline Grau & Nome3 & Cidade & $\begin{array}{l}\text { Faixa } \\
\text { preta Ano }\end{array}$ & $\begin{array}{l}\text { Tempo } \\
\text { entrevista }\end{array}$ \\
\hline Grão Mestre & Welington “Narany" Luiz da Silva & Rio de Janeiro & 1979 & $1 \mathrm{~h} 54$ \\
\hline Mestre & $\begin{array}{l}\text { Antônio "Reginaldo China" Moreira } \\
\text { da Silva }\end{array}$ & Curitiba & 1983 & $1 \mathrm{h06}$ \\
\hline Professor & $\begin{array}{l}\text { Júlio Cesar “Carioca" de Souza } \\
\text { Regueira }\end{array}$ & $\begin{array}{l}\text { Curitiba / Rio } \\
\text { de Janeiro }\end{array}$ & 1984 & $2 \mathrm{h03}$ \\
\hline Grão Mestre & "Rudimar Fedrigo" & Curitiba & 1984 & Oh:47 \\
\hline Grão Mestre & "Fábio" Seuchi "Noguchi" & Curitiba & 1985 & 0h54 \\
\hline Grão Mestre & "Augusto" Cesar Cunha & Rio de Janeiro & 1986 & $1 \mathrm{~h} 33$ \\
\hline Grão Mestre & "Sandro" Roberto Batista “Lustosa" & Rio de Janeiro & 1989 & $2 \mathrm{~h} 16$ \\
\hline Grão Mestre & "Edinei” Carlos "Pedroso" & Curitiba & 1992 & $1 \mathrm{~h} 12$ \\
\hline
\end{tabular}

Fonte: Os autores

2 Este estudo foi homologado e aprovado pelo Comitê de Ética em Pesquisa do Instituto de Ciências Humanas da Universidade de Brasília - CEP/IH, mediante o parecer consubstanciado número 1.469.110. A inscrição do projeto junto ao Comitê Nacional de Ética em Pesquisa (CONEP) pode ser localizada no site "Plataforma Brasil" a partir do número de registro: 51225615.5 .0000 .5540 .

3 O nome, sobrenome ou apelido em negrito, representa a forma como será referida a narrativa do entrevistado. 
A escolha dos entrevistados seguiu os seguintes critérios de inclusão: 1) praticantes da modalidade que conviveram e treinaram com Nélio Naja; 2) se graduaram faixa preta; 3) fizeram parte das primeiras gerações do Muay Thai brasileiro.

Welington Narany foi o primeiro faixa preta formado por Nélio Naja em maio de 1979. Reginaldo China, treinou e ministrou aulas na academia MUAYTHAI fundada por Nélio Naja. Júlio Cesar "Carioca "conheceu Nélio Naja na época em que ele iniciou seu trabalho com o Taekwondo em Curitiba, também treinou o Boxe Tailandês em Curitiba e Rio de Janeiro. Rudimar Fedrigo foi o primeiro aluno a se desvincular do sistema de treinamento de Nélio Naja e montar sua própria metodologia, fundando a academia Chute Boxe. Fábio Noguchi conheceu Nélio Naja no período em que ele estava regressando ao Rio de Janeiro, indo até lá realizar o exame de faixa preta. "Augusto" Cunha conviveu com Nélio Naja no regresso ao Rio de Janeiro. Sandro Lustosa participou da primeira excursão carioca que foi à Curitiba junto com Welington Narany e Flávio Molina treinar e conhecer Nélio Naja em 1980. Edinei Pedroso conviveu com Nélio Naja nos últimos anos de vida, após ele regressar a Curitiba.

Após cada entrevista, foi realizado a passagem do oral para o escrito, baseado nos conceitos de Alberti (2013), denominado de "processamento", que compreende as etapas de transcrição, conferência de fidelidade da transcrição e copidesque ${ }^{4}$.

Ao partir da ideia de que toda a história retrata a passagem do ponto "a" para o ponto "b", podemos compreender a jornada do herói de Joseph Campbell, em seus livros: O Herói de Mil Faces (1949) e O Poder do Mito (1990). Estas obras ajudam a compreender como o mito é produzido. Campbell engrandece o entendimento ao afirmar: "Pois os símbolos da mitologia não são fabricados: não podem ser ordenados, inventados ou permanentemente suprimidos. Esses símbolos são produções específicas da nossa psique e cada um deles traz em si, intacto, o poder criador da fonte" (CAMPBELL, 1949, p. 07).

Campbell (1949) retrata a busca visionária do mito, onde todos e têm a mesma forma e o mesmo esforço essencial em todas as mitologias. As narrativas são sempre apresentadas em três atos: a partida, realização do feito e o retorno. A saga começa ao deixar o mundo onde está e se encaminha na direção de algo mais profundo, mais distante ou superior. Então ao conquistar aquilo que faltava à sua consciência, no mundo anteriormente habitado, o herói regressa ao seu mundo social. As distintas seções foram estruturadas a partir desta trajetória estabelecida por Campbell (1949, 1990).

\section{A PREPARAÇÃO - O INÍCIO NO TAEKWONDO}

O Taekwondo chegou ao Brasil em 1970 na cidade de São Paulo, trazido por Sang Min Cho e outros, como Sang Min Kim, Kun Mo Bang, que fundaram a "Academia Liberdade". Dois meses depois chegaram ao Brasil Kum Joon Kwon e Woo Jae Lee (RIOS, 2005; MÜLLER; ETO, 2014). 
No livro intitulado "Defesa Pessoal: Hoshin-sull do taekwondo", Woo Jae Lee comenta que conheceu Nélio Naja na academia Frama, localizada no Aterro do Flamengo, no Rio de Janeiro, em 1972, e que se destacou entre os primeiros alunos que praticaram a modalidade. "Ele foi o primeiro aluno que pulou da graduação $10^{\circ}$ Gub (faixa branca) direto para $6^{\circ} \mathrm{Gub}$ (faixa verde). Com a faixa verde virou ajudante de seu mestre, demonstrando disciplina e fazendo as posições com perfeição (LEE, 2019).

Após quatro anos de treinamento e auxiliar seu mestre diversas vezes ministrando aulas, Nélio Naja conquistou o primeiro dan (faixa preta) em 1976. Após esta conquista ele começou a se distanciar de Woo Jae Lee, pois seu mestre estava muito ocupado com a Confederação Brasileira de Pugilismo (CBP). Woo Jae Lee permaneceu na CBP por 13 anos, até a criação em 1987 da Associação Brasileira de Taekwondo (ABT), renomeada posteriormente Confederação Brasileira de Taekwondo (CBTKD), em 1990 (AFONSO, 2012).

\section{3 “GUIADO PELA INTUIÇÃO” - A PARTIDA}

Nélio Naja sonhava viver e sustentar sua família dando aula de Taekwondo, mas no Rio de Janeiro seria difícil, pois dois dos principais mestres (Woo Jae Lee e Yong Min Kim) estavam ministrando aulas da modalidade (LEE, 2019). O primeiro estágio desta saga foi abandonar o ambiente familiar e migrar para outra cidade, optando pela cidade de Curitiba (CAMPBELL, 1990). A escolha da cidade se deu por um motivo inusitado. Em entrevista ao Jornal Gazeta do Povo, publicada no dia 25 de fevereiro de 2007, Nélio Naja afirmou que "[...] na época frequentava um templo místico, a escolha da cidade para iniciar o muay thai no Brasil foi guiada pela minha intuição espiritual. Simplesmente achei que Curitiba seria o lugar certo" (CIDADE, 2007).

No ano de 1976, Nélio Naja mudou-se para Curitiba. Em um primeiro momento iniciou ministrando aulas da modalidade coreana, sem muitos alunos e com a chegada do mestre Hong Soon Kang à cidade, ele passa por uma série de provações (informação verbal) ${ }^{5}$. Após superar o périplo ${ }^{6}$ universal do herói ele adaptou as técnicas orientais [Taekwondo] para criar o Muay Thai brasileiro no ano de 1979 (RUDNICK, 2015; INTRODUTOR, 2016).

\section{4 “UMA VERSÃO DIFERENTE” - O FEITO}

Os entrevistados rememoraram o início do Muay Thai a partir do momento em que Nélio Naja começou dando aulas em algumas praças. Após um curto período na Vila Guaíra ${ }^{7}$, Nélio Naja começa a ministrar aulas no centro da cidade, um dos primeiros locais foi a academia Muzenza, era uma academia de diversas modalidades. Ele deu

\footnotetext{
5 Entrevista concedida por REGUEIRA, Júlio Cesar de Souza. [08. 2019]. Entrevistador: Ivo Lopes Müller Júnior. Balneário Camboriú, 2019. Arquivo mp3 (2h:03).

6 "[...] Evoluir da posição de imaturidade psicológica para a coragem da auto responsabilidade e a confiança exige morte e ressurreição. Esse é o motivo básico do périplo universal do herói - ele abandona determinada condição e encontra a fonte da vida, que o conduz a uma condição mais rica e madura" (CAMPBELL, 1990, p. 138).

7 Bairro residencial da cidade de Curitiba, localizado a seis quilômetros do centro da cidade, começou a se popularizar na década de 1970.
} 
aula no Colégio Militar de Curitiba, ficou por um tempo no clube "Sociedade Thalia" e no "Círculo Militar do Paraná9, até montar sua própria academia denominada MUAYTHAI, localizada no centro da cidade, mais precisamente na rua Carlos de Carvalho, 256

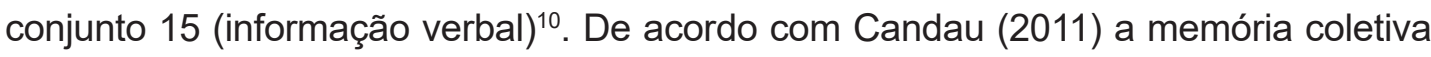
está imbricada na construção da identidade do Muay Thai brasileiro, pois:

[...] ao mesmo tempo em que nos modela, é também por nós modelada. Isso resume perfeitamente a dialética da memória e da identidade que se conjugam, se nutrem mutuamente, se apoiam uma na outra para produzir uma trajetória de vida, uma história, um mito, uma narrativa "grifo do autor". (CANDAU, 2011, p. 16).

As narrativas se divergem em relação a como o introdutor conheceu o Muay Thai. Segundo a versão retratada por Welington Narany, Fábio Noguchi e Rudimar Fedrigo, um membro da família (pai ou irmão) conheceu um tailandês, que ficou hospedado por um tempo na casa da família e ensinou o Muay Thai ao Nélio Naja. Narany ressaltou que "Ele [Nélio] não era muito folclórico, de falar muito, disso ou daquilo, não. Ele era muito direto, que conheceu os tailandeses, e gostou do esporte, abandonou totalmente o Taekwondo para se dedicar a nova modalidade" (informação verbal) ${ }^{11}$.

Ao ser questionado a respeito de como teria ocorrido o contato com os tailandeses, Rudimar Fedrigo (informação verbal) ${ }^{12}$ afirmou: "Eu não... [pensativo] Eu era um garoto quando isso aconteceu. Eu soube dessas informações que ele mesmo me contou".

Os entrevistados Reginaldo China, Júlio Cesar "Carioca" (informação verbal) ${ }^{13}$ apresentaram uma versão diferente, questionando o fato dele ter treinado na Tailândia. Para eles, Nélio Naja, teria conhecido a modalidade aqui no Brasil, através da embaixada da Tailândia. Por ser militar, ele supostamente teve contato com os seguranças da embaixada que eram militares e lutadores tailandeses. Eles provavelmente teriam ensinado o Muay Thai ao Nélio Naja. Segundo suas narrativas, nessa época ele já era faixa preta de Taekwondo. Reginaldo China ressalta em sua narrativa que Nélio Naja era muito reservado em relação ao seu passado.

No livro intitulado "Diamante - A História de Luiz Alves Lenda do Muay Thai e MMA" escrito por Claudia Reis e José Alberto Rodrigues há o seguinte relato:

Nélio, paraquedista militar e também faixa preta em Taekwondo, havia passado dois anos em Bangkok, capital da Tailândia, onde se especializou em Muay Thai. A história que ele contou para a turma da Naja, segundo lembra mestre Aroldo Vieira, que integrava a equipe de Molina, era que

8 A Sociedade Thalia foi fundada em 1882, tendo sua origem ligada à colonização alemã. O clube era elitizado, com sua sede localizada no centro da cidade de Curitiba (MEZZADRI, 1999).

9 O Clube Círculo Militar do Paraná foi fundado em 1939. Na década de 1940, o Círculo Militar do Paraná era um dos pontos mais badalados de Curitiba, coma presença do governador e os militares (HISTÓRIA, 2019).

10 Entrevista concedida por FEDRIGO, Rudimar. [07. 2019]. Entrevistador: Ivo Lopes Müller Júnior. Curitiba, 2019. arquivo mp3 (Oh:47). Entrevista concedida por NOGUCHI, Fábio Seuchi. [07. 2019]. Entrevistador: Ivo Lopes Müller Júnior. Curitiba, 2019. Arquivo mp3 (Oh:54). Entrevista concedida por PEDROSO, Edinei Carlos [07. 2019]. Entrevistador: Ivo Lopes Müller Júnior. Curitiba, 2019. arquivo mp3 (1h:12).

11 Entrevista concedida por SILVA, Welington "Narany" Luiz da. [08. 2019]. Entrevistador: Ivo Lopes Müller Júnior. Vila Velha, 2019. arquivo mp3 (1h:54).

12 Entrevista concedida por FEDRIGO, Rudimar. [07. 2019]. Entrevistador: Ivo Lopes Müller Júnior. Curitiba, 2019. arquivo mp3 (0h:47).

13 Entrevista concedida por MOREIRA DA SILVA, Antônio "Reginaldo China". [07. 2019]. Entrevistador: Ivo Lopes Müller Júnior. Curitiba, 2019. arquivo mp3 (1h:06). Entrevista concedida por REGUEIRA, Júlio Cesar de Souza. [08. 2019]. Entrevistador: Ivo Lopes Müller Júnior. Balneário Camboriú, 2019. arquivo mp3 (2h:03). 
por ser budista, religião predominante na Tailândia, havia ganhado uma passagem de um grupo de religiosos para disputar um mundial de Taekwondo no País. Ao descobrir o Muay Thai, decidiu ficar por lá para aprender a arte marcial. Foi assim que o Nélio Naja conheceu o Muay Thai, que a gente chamava de Boxe Tailandês. Ele mesmo contou isso "grifo do autor". (REIS; RODRIGUES, 2018, p. 42).

Termos apresentados nas narrativas como "o próprio Nélio contava", "a história tradicional dele", "foi o que ouvi falar", "sempre ouvi dizer", "ele mesmo me contou" demonstram insegurança dos entrevistados ao revelar a verdade e a reconstrução contínua do passado (PORTELLI, 2016). De acordo com Candau (2011) a memória não é estática, ela é a atualização e reconstrução contínua do passado, o pensamento segundo o qual as vivências passadas seriam memorizadas, estáticas e recuperadas na íntegra. Aparenta ser "insustentável".

Segundo Thompson (1992), na tentativa de manter a verdade "oculta" o mestre Edinei Pedroso (informação verbal) ${ }^{14}$ explicou: "[...] acho que não sou a pessoa mais correta para falar sobre isso agora, por que vai muito tempo". Existem duas ou três versões "[...] acho que não sou a pessoa mais correta para falar do assunto, apesar de saber as três versões, deixamos isso para outra pauta".

Podemos considerar que "[...] as dificuldades e bloqueios que eventualmente surgiram ao longo de uma entrevista raramente resultavam de brancos da memória ou de esquecimentos, mas de uma reflexão sobre a própria utilidade de falar e transmitir seu passado" (POLLAK, 1989, p.13). Esses silenciamentos exibidos em algumas narrativas foram apresentados pelo fato de que "[...] mesmo no nível individual o trabalho da memória é indissociável da organização social da vida" (POLLAK, 1989, p. 15).

A linha tênue entre a fronteira do narrável e do inarrável se apresenta nessas falas, pois, ao revelar a verdade, os entrevistados temem colocar o presente em cheque, remodelar a história e manchar a honra de um mito (PORTELLI, 2016). Abrindo espaço para que outro indivíduo assuma o posto de introdutor da modalidade no Brasil.

Os mestres pioneiros tiveram que usar da criatividade para aprimorar suas técnicas. Numa época em que não se tinha acesso à internet, conseguir informações a respeito da modalidade era muito difícil (informação verbal) ${ }^{15}$. Coincidentemente - ou nem tanto - o desenho Sawamu passou a ser transmitido no Brasil na mesma época em que Nélio iniciava seus trabalhos com o Muay Thai. Segundo Reis e Rodrigues (2019, p. 59), "[...] não deixa de ser pitoresco o fato deles [os mestres pioneiros] terem recorrido a um desenho de animação - Sawamu [...] que mostrava todas as técnicas do Muay Thai e tinha muito a ver com o treino da gente. Este desenho nos ajudou muito".

O desenho animado baseado em fatos reais foi produzido no Japão por lkki Kajiwara (roteiro), Kentaro Nakajiro (desenho) e Toei Animatione (produção), contava com 26 episódios de aproximadamente 30 minutos. No Brasil, foi transmitido em canal

14 Entrevista concedida por PEDROSO, Edinei Carlos [07. 2019]. Entrevistador: Ivo Lopes Müller Júnior. Curitiba, 2019. Arquivo mp3 (1h:12).

15 Entrevista concedida por CUNHA, Augusto Cesar. [09. 2019]. Entrevistador: Ivo Lopes Müller Júnior. Rio de Janeiro, 2019. Arquivo mp3 (1h:33). 
aberto no ano de 1976, pela TV Record, no horário das 18 horas, permanecendo no ar por dois anos, sempre no mesmo horário. Em 1979 passou a ser transmitido pela TV Gazeta, ficando alguns meses na programação. Retornou à televisão brasileira em 1983, novamente pela TV Record, sendo exibido às 14 horas. Deixou de ser exibido definitivamente em 1984 (DESENHO, 2019).

O desenho animado descreve a história do lutador Tadashi Sawamura. Este era originário do Caratê e desafiou um lutador de Boxe Tailandês, mas perdeu uma das batalhas. Posteriormente, se engajou em treinar arduamente o Muay Thai. Assim venceu vários tailandeses e ajudou a criar e difundir o Kickboxing Japonês.

Os entrevistados Rudimar Fedrigo, Augusto Cunha, Sandro Lustosa e Welington Narany, rememoraram a influência do desenho animado no desenvolvimento do Muay Thai brasileiro. Júlio Cesar "Carioca" (informação verbal) ${ }^{16}$ conheceu o desenho na época em que Nélio Naja ainda dava aula de Taekwondo em Curitiba, no final da década de 1970. De acordo com o grão mestre Sandro Lustosa, Sawamu foi determinante para a introdução e desenvolvimento da modalidade no Brasil.

\begin{abstract}
O melhor lutador que nós tínhamos visto de boxe tailandês era um personagem de desenho animado, o Sawamu. [...] Sem dúvida nenhuma os filmes do Bruce Lee influenciaram a questão do kung fu e da arte marcial em geral, mas o desenho animado Sawamu foi determinante. Nós somos da época do Sawamu. Nós que somos da época da introdução do Muay Thai aqui no RJ através do Flávio Molina, Welington Narany e Nélio Naja, fomos influenciados pelo desenho (informação verbal) ${ }^{17}$.
\end{abstract}

Após ter abandonado o Caratê para se dedicar ao Boxe Tailandês, Sawamu passa ser visto como um traidor por seus amigos e admiradores. Ele passa a realizar um longo e árduo treinamento. Uma das principais características da nova modalidade é a força aplicada nos golpes e a intensa preparação física que incluía corrida de rua, subir montanhas e chutar árvores (NAGADO; MATSUDA; DE GOES, 2011).

Depois que Sawamu vence alguns lutadores tailandeses, fica decidido que o nome do estilo seria Kickboxing (na tradução brasileira para Chute Boxe). Esse fato inspirou o nome da equipe formada pelo grão mestre Rudimar Fedrigo (informação verbal $)^{18}$ no início da década de 1980 . Ele comentou que um dos motivos de sua saída da academia Muay Thai e da criação da equipe Chute Boxe foi o fato de que Nélio Naja "[...] utilizava um sistema de treinamento muito voltado para o aspecto militar, pois [supostamente] era paraquedista. Ele gostava muito disso, aí começamos a divergir um pouco sobre este aspecto" (informação verbal) ${ }^{19}$.

Todos os entrevistados relataram a paixão de Nélio Naja pelo aspecto militar, alguns acreditaram fielmente na narrativa produzida pelo mesmo, que supostamente teria sido paraquedista no Batalhão de Infantaria da Aeronáutica - BINFA. Segundo Augusto Cunha, Nélio Naja queria muito ter sido paraquedista das forças armadas,

\footnotetext{
16 Entrevista concedida por REGUEIRA, Júlio Cesar de Souza. [08. 2019]. Entrevistador: Ivo Lopes Müller Júnior. Balneário Camboriú, 2019. arquivo mp3 (2h:03).

17 Entrevista concedida por LUSTOSA, Sandro Roberto Batista. [07. 2019]. Entrevistador: Ivo Lopes Müller Júnior. Rio de Janeiro, 2019. arquivo mp3 (2h:16).

18 Entrevista concedida por FEDRIGO, Rudimar. [07. 2019]. Entrevistador: Ivo Lopes Müller Júnior. Curitiba, 2019. arquivo mp3 (0h:47)

19 Entrevista concedida por FEDRIGO, Rudimar. [07. 2019]. Entrevistador: Ivo Lopes Müller Júnior. Curitiba, 2019. arquivo $\mathrm{mp} 3$ (0h:47).
} 
realizou alguns cursos, vivenciava aquilo 24 horas, buscava se portar e se vestir como um militar, valorizava a amizade com pessoas que teriam sido militares, como apresentado nas entrevistas de Reginaldo China e Júlio Cesar "Carioca". Nélio Naja incorporou os aspectos militares a sua identidade a ponto de muitos acreditarem realmente que ele foi paraquedista militar (CANDAU, 2011; POLLAK, 1992).

A escola de paraquedistas foi criada em 1945. Em 1957, foi realizado o primeiro Curso de Operações Especiais. Durante o curso, 16 militares realizaram o primeiro salto livre militar no Brasil. Em 1971, foi realizado o primeiro Curso de Ações de Comandos e a Brigada Aero terrestre mudou a sua denominação para Brigada Paraquedista. Ao longo das últimas décadas, o grupo boina bordô e as asas de prata têm conquistado a confiança e o respeito dos cidadãos brasileiros e também da comunidade internacional, devido à participação dos paraquedistas do exército brasileiro em diversas operações de paz da ONU. Estes grupos integraram operações na África (Moçambique, em 1994, e Angola, de 1995 a 1997); na Ásia (Timor Leste, em 2002) (MENEZES, 2019).

Nélio nasceu em 29 de novembro de 1952. Muito provavelmente, se chegou a servir as forças armadas brasileiras, teria sido entre os anos de 1971 e 1972. Embora, via contato telefônico, a secretaria do BINFA informou que ele não prestou serviço militar na Aeronáutica. Ao analisar o histórico da Brigada de Infantaria Paraquedista - BDAINFPQDT pode-se verificar que as primeiras missões internacionais foram realizadas a partir da década de 1990. A primeira missão da brigada de paraquedistas na Ásia ocorreu em Timor Leste no ano de 2002 e não na década de 1970 como afirmou Nélio Naja, justificando sua suposta ida à Tailândia.

\section{5 "PASSAVA UMA TEMPORADA ALI E OUTRA EM CURITIBA" - O RETORNO AO RIO DE JANEIRO}

Devido ao fato de ter parentes na ilha do Governador, Nélio Naja, esporadicamente, passava uma temporada ali e outra em Curitiba (informação verbal $)^{20}$. No início do ano de 1979 , numa dessas viagens, ele encontrou seu amigo Nilo ${ }^{21}$ que realizava um treino com Welington Narany no aterro do Flamengo. Nélio Naja comentou que estava instituindo o Boxe Tailandês convidou os dois para conhecer a modalidade. Narany aceitou o convite, gostou tanto do treinamento que no mês de abril do mesmo ano foi à Curitiba, passou um mês treinando de forma intensa com Nélio Naja e recebeu o certificado de faixa preta. Como Narany já era faixa preta de Taekwondo teve facilidade em aprender o Boxe Tailandês e se tornou o primeiro faixa preta formado por Nélio Naja no dia 17 de maio de 1979.

Embora tenha começado seus trabalhos em Curitiba, O Grão Mestre Nélio Naja formou seus primeiros discípulos oriundos da cidade do Rio de Janeiro. Os primeiros faixas pretas foram Welington Narany e Flávio Molina; logo em seguida, Luiz Alves. A primeira geração do Muay Thai curitibano foi formada por Reginaldo

20 Entrevista concedida por SILVA, Welington "Narany" Luiz da. [08. 2019]. Entrevistador: Ivo Lopes Müller Júnior. Vila Velha, 2019. arquivo mp3 (1h:54).

21 Nilo Vaz da Silva foi um dos primeiros faixas pretas de Taekwondo formados no Rio de Janeiro por Woo Jae Lee. No ano de 1978, ele, Welington Narany e Flávio Molina fundaram a academia NAJA. A academia foi oficialmente registada no dia 29 de setembro de 1978 (REIS; RODRIGUES, 2018). 
Moreira "China", Ranhs, Ramalhete, Ricardo Romaneto, Rubens Melantonio Filho e Rudimar Fedrigo - fundador da academia Chute Boxe.

Fabio Noguchi (informação verbal)22 conheceu Nélio Naja no ano de 1981. Ele estava prestes a voltar para o Rio de Janeiro. Quem ficou dando aula na academia MUAYTHAI foi o Rubens no período da noite e o Reginaldo China no período da tarde. O introdutor da modalidade ficou por um tempo dando aula na academia Naja e disseminando a modalidade em sua cidade natal.

A modalidade rapidamente ganhou o gosto dos cariocas. Narany e Flávio Molina começaram a dar aula em várias academias do Rio de Janeiro. Com o desenvolvimento da modalidade e o aumento do número de participantes começam a surgir as primeiras competições. O primeiro torneio interestadual foi organizado por Nélio Naja, Welington Narany e Flávio Molina e foi denominado: "desafio Curitiba Rio de Janeiro" em 1981.

Após muito trabalho, planejamento e investimento o Muay Thai se tornou sucesso no país. Em entrevista concedida a rede bandeirantes de televisão, Flávio Molina afirmou que em cinco anos a modalidade contava com vinte professores e mais de cinco mil praticantes na cidade do Rio de Janeiro. O jornal Correio de Notícias do dia 1 de Junho de 1988 informou que em Curitiba já existiam quatro academias da modalidade com mais de mil participantes; comunicava ainda que para o desafio Curitiba - Rio de Janeiro II, realizado no Clube Círculo Militar de Curitiba, foram vendidos mais de 2000 ingressos antecipados (BOXE, 1988).

\section{6 "TEVE UMA FASE QUE ELE FEZ ISSO" - UMA NOVA SAGA}

Em uma das melhores fases do Muay Thai brasileiro, com a modalidade despontando em Curitiba e Rio de Janeiro, Nélio abandonou tudo em busca de uma aventura, de um sonho. Ele estava muito entusiasmado com o ouro, da Serra Pelada, deslumbrava ficar rico através da mineração e, assim, entrou na chamada "febre do ouro".

Nélio teve muitos alunos [ênfase] só que ele era uma pessoa, muito, [pensativo] com a mente muito, como posso explicar? Ele estava numa fase com a academia lotada, bombando de gente, numa fase muito boa e ele resolveu ir achar ouro. Se embrenhou no interior do Pará. Pegou doença, mudava muito o foco, pessoa muito criativa, deslumbrada e teve uma fase que ele fez isso (informação verbal) ${ }^{23}$.

Em entrevista ao jornalista Fernando Rudnick, o próprio Nélio Naja comentou que teria saído em busca de ouro e pedras preciosas no Serrado e teria caído num golpe (RUDNICK, 2015). No final da década de 1980, ao abandonar o garimpo, voltou ao Rio de Janeiro, ficou por aproximadamente dois anos dando aula na academia Naja, até se desentender com Welington Narany. O introdutor da modalidade queria seguir a tendência de algumas modalidades, cobrar uma taxa para realizar o exame pleiteando a faixa preta e cobrar a mais por aulas individualizadas. Atitudes que Welington Narany discordava.

22 Entrevista concedida por NOGUCHI, Fábio Seuchi. [07. 2019]. Entrevistador: Ivo Lopes Müller Júnior. Curitiba, 2019. arquivo mp3 (0h:54).

23 Entrevista concedida por FEDRIGO, Rudimar. [07. 2019]. Entrevistador: Ivo Lopes Müller Júnior. Curitiba, 2019. arquivo mp3 (0h:47). 
Após sair da academia Naja, o introdutor da modalidade, passou a morar em diversas cidades. "Nélio se define como um ermitão. Optou pelo isolamento e transformou seu paradeiro em quase segredo de estado." (RUDNICK, 2015). Segundo Campbell (1990) para o mito o importante é viver a vida em busca de experiências, de conhecimentos, do mistério intrínseco da vida e do seu próprio mistério.

Na década de 1990, O Muay Thai brasileiro começa a se destacar em eventos de Mix Martial Arts (MMA), principalmente através da academia Chute Boxe, eleita umas melhores academias do mundo (ALBUQUERQUE, 2016). Nesta época, os primeiros professores da modalidade começaram a formar vários alunos grau $^{24}$ preto, surgindo a figura do mestre e Grão Mestre. Retornado a figura do grão-mestre Nélio Naja como "a personificação do Muay Thai nacional" (informação verbal $)^{25}$.

Júlio Cezar "Carioca" chegou a levar Nélio Naja para dar aula de Muay Thai na guarda municipal do Rio de Janeiro, e em algumas academias, mas ele já não queria mais saber da modalidade (informação verbal) ${ }^{26}$. Para Nélio Naja, falar a respeito do Muay Thai era como falar de um amor superado, sem vínculo algum, apenas uma relação saudosa, separada por um cânion (RUDNICK, 2015).

No ano 2000 Nélio Naja criou o Kuro Tora, que seria uma arte marcial voltada para técnicas de combate e sobrevivência (informação verbal) ${ }^{27}$. Júlio Cesar "Carioca" informou que ele queria resgatar sua metodologia utilizada na década de 1970, com o quebramento de telhas, o Tude ${ }^{28}$, luta com armas (faca, facão, bastão) e um sistema diferenciado de graduações. Nélio Naja não conseguiu perceber que o mercado não aceitaria a demanda de uma nova modalidade; queriam ver o introdutor do Muay Thai e não o criador de uma nova arte marcial.

\section{7 "SOU FELIZ DIANTE DAS DIFICULDADES" - O RETORNO A CURITIBA}

No início da década de 2010, o introdutor da modalidade chegou a morar por alguns anos dentro de um ônibus abandonado numa escola de treinamento tático para policiais e militares na cidade de Curitiba, depois que perdeu contato com a esposa e os três filhos" (RUDNICK, 2015).

O programa Globo Esporte realizou uma série de matérias especiais sobre o MMA no Paraná, motivado pela realização do UFC 198, na cidade de Curitiba, que ocorreria em maio de 2016. A primeira reportagem foi ao ar no dia 05/01/2016 e trouxe à tona a situação em que estava vivendo Nélio Naja. Morando numa casa inacabada,

\footnotetext{
24 No início dos anos 1990, após o Conselho Nacional de Desportes - CND estabelecer as normativas para se padronizar a modalidade no país a graduação deixou de ser utilizada como faixa na cintura e passou a ser utilizada no braço por uma trama de fios ou tecido torcido, denominado de "grau".

25 Entrevista concedida por REGUEIRA, Júlio Cesar de Souza. [08. 2019]. Entrevistador: Ivo Lopes Müller Júnior. Balneário Camboriú, 2019. arquivo mp3 (2h:03).

26 Entrevista concedida por SILVA, Welington "Narany" Luiz da. [08. 2019]. Entrevistador: Ivo Lopes Müller Júnior Vila Velha, 2019. arquivo mp3 (1h:54).

27 Entrevista concedida por SILVA, Welington "Narany" Luiz da. [08. 2019]. Entrevistador: Ivo Lopes Müller Júnior. Vila Velha, 2019. arquivo mp3 (1h:54).

28 O Tudê era uma mistura de kata (exercícios pré determinados contra um oponente imaginário) com exercício de defesa pessoal composto por 50 sequências de golpes.
} 
feita por um amontoado de tijolos e parcialmente coberta por um rústico telhado, ele sonhava em ter um terreno para poder voltar a dar aula. Nélio Naja comentou também a respeito das desilusões no esporte e que eram difíceis para ele rememorar. "Foi uma decepção, porque em todas as portas que eu bati, bateram a porta mais alto. É como você dar um presente e ele ser jogado no chão. Foi como me senti. Não tenho mágoa e nem rancor, mas foi como me senti” (INTRODUTOR, 2016). De acordo com Campbell (1990) todos os mitos lidam justamente com a transformação da consciência. Com postura altruísta ele complementa: "Sou feliz diante das adversidades, isso me torna melhor". Quanto ao seu papel no desenvolvimento da modalidade ele pondera: "[...] Se não fosse eu, outro qualquer ocuparia esse espaço" (RUDNICK, 2015).

Nélio Naja faleceu no dia 12 de julho de 2017, aos 65 anos, de morte natural em casa. Ao ensinar a enfrentar o sofrimento (CAMPBELL, 1949) amigos e alunos preferem que o mestre seja lembrado como um mito, forte e guerreiro (SOUZA, 2018). A despedida do grão-mestre Nélio Naja teve que ser breve, devido à dificuldade em localizar a família para liberar o corpo "[...] visto que a relação de Nélio Naja com parentes já não existia há muito tempo. "[...] Nos últimos anos, Mestre Nélio Naja vivia uma vida reclusa, quase como um 'Ermitão'. Nem por isso, no entanto, deixou de ter amigos e seguidores" (SOUZA, 2018).

Segundo as narrativas dos entrevistados, Nélio Naja é considerado um mito, um herói lendário introdutor de uma das mais eficientes modalidades de esporte de combate no Brasil. Ao "[...] pensar em termos mitológicos ajuda-o a se colocar em acordo com o que há de inevitável neste vale de lágrimas. Você aprende a reconhecer os valores positivos daqueles que aparentam ser os momentos e aspectos negativos da sua vida" (CAMPBELL, 1990, p. 181).

\section{CONSIDERAÇÕES FINAIS}

Nélio Naja foi um dos primeiros faixas pretas de Taekwondo formados no Brasil. Ele treinou entre os anos de 1972 a 1976. Naja incorporou os aspectos militares a sua identidade a ponto de muitos acreditarem realmente que ele foi paraquedista militar (CANDAU, 2011). Embora o BINFA tenha negado via contato telefônico que Nélio Borges de Souza tenha sido paraquedista da aeronáutica, não foi possível concluir se ele realmente serviu as forças armadas. Se isso realmente ocorreu, foi possivelmente entre os anos de 1971 a 1972.

No ano de 1976, "guiado por sua intuição espiritual" escolheu a cidade de Curitiba para morar. Residiu na capital paranaense por seis anos (CIDADE, 2007). Nélio iniciou ministrando aula de Taekwondo, realizou algumas adaptações e criou sua própria versão do boxe tailandês" (RUDNICK, 2013).

Indícios apresentados nas falas dos entrevistados e nas datas em que foi transmitido em canal aberto a série de desenho animado Sawamu apontam para a inspiração por parte de Nélio Naja ao iniciar e lapidaros trabalhos com o Boxe Tailandês. Se o desenho não foi a inspiração, de certa forma, auxiliou no desenvolvimento dos treinamentos, pois a forma de ensinamento realizado por Nélio Naja se aproximava muito da apresentada no desenho Sawamu. 
A partir da socialização com seus alunos, Nélio Naja começou a inculcar algumas ideias a respeito de como tinha conhecido a modalidade. Moldou um sistema de valores e padrões de comportamento, que foi sendo repassado de aluno para aluno e cristalizando sua versão histórica a respeito de como conheceu a modalidade. Ao produzir três versão, o mito se contradiz, apresentando indícios de que nunca esteve na Tailândia, e que criou a modalidade a partir do Taekwondo. "Sua memória, contudo, pode sobreviver a seu desaparecimento, assumindo em geral a forma de um mito que, por não poder se ancorar na realidade política do momento, alimenta-se de referências culturais, literárias ou religiosas" (POLLAK, 1989, p.11).

Importante ressaltar que independente da forma como Nélio Naja aprendeu, pesquisou e desenvolveu a modalidade, seu nome deve ser respeitado. Ele foi o primeiro a desenvolver um sistema de treinamento especializado, instituir um sistema de graduação, disseminar a modalidade para outros estados e organizar as primeiras competições de Muay Thai no país.

\section{REFERÊNCIAS}

AFONSO, José. 38 anos de Taekwondo "oficial” no Brasil. 2012. Disponível em: http:// www.tkdlivre.com/index.php?option=com content\&view=article\&id=644:38-anos-detaekwondo-oficial-no-brasil\&catid=4:cultura-marcial\&ltemid=5. Acesso em: 5 ago. 2019.

ALBERTI, Verena. Manual de história oral. 3. ed. Rio de Janeiro: FGV, 2013.

ALBUQUERQUE, Adriano et al. Especial Chute Boxe, a equipe que fez Curitiba se tornar a Tailândia brasileira. Caderno Combate. 2016. Disponível em: http://sportv.globo. $\mathrm{com} / \mathrm{site} / \mathrm{comb}$ ate/noticia/2016/05/especial-chute-boxe-equipe-que-fez-curitiba-se-tornartailandia-brasileira.html. Acesso em: 7 maio 2019.

ALVES, Luiz; MARIANO, Artur. Muay Thai: Boxe Thailandês. São Paulo: On Line, 2007.

BOXE Tailandês. Correio de Notícias, p. 15. $1^{\circ}$. jun. 1988. Disponível em: http://memoria. bn.br/DocReader/DocReader.aspx?bib=325538 01\&pesq=boxe \%20tailand\%C3\%AAs .

Acesso em: 5 maio 2019.

BOWMAN, Paul. Making Martial Arts History Matter. The International Journal of the History of Sport, v. 33, n. 9, p. 915-933, 2016.

CAMPBELL, Joseph. O Poder do Mito. São Paulo: Palas Athena, 1990.

CAMPBELL, Joseph. O Herói de Mil Faces. São Paulo: Pensamento, 1949.

CANDAU, Joel. Memória e Identidade. São Paulo: Contexto, 2011.

CIDADE foi Escolhida por Intuição Mística. Curitiba, 25 fev. 2007. Disponível em: https://www.gazetadopovo.com.br/esportes/cidade-foi-escolhida-por-intuicao-misticaadr1kmw3edrpwfusnk0wg8z0ul . Acesso em: 06 maio 2019.

DESENHO Sawamu. 2019. Disponível em: http://infantv.com.br/infantv/?p=4580 . Acesso em: 3 abr. 2019 
HISTÓRIA, o começo de um dos maiores clubes do Brasil. Curitiba: Círculo Militar do Paraná, 2019. Disponível em: https://www.clubecirculo.com.br/historial. Acesso em: 3 maio 2019.

INTRODUTOR do Muay Thai no Brasil vive isolado e esquecido no Paraná. Almirante Tamandaré, 5 jan. 2016. Disponível em: http://globoesporte.globo.com/pr/noticia/2016/01/ introdutor-do-muay-thai-no-brasil-vive-isolado-e-esquecido-perto-de-curitiba.html. Acesso em: 5 maio 2019.

LEE, Woo-Jae. Defesa Pessoal: Hoshin-sull do taekwondo. Santos: Bueno, 2019.

LISE, Riqueldi Straub; CAPRARO, André Mendes. Primórdios do jiu-jitsu e dos confrontos intermodalidades no Brasil: contestando uma memória consolidada. Revista Brasileira de Ciências do Esporte, v. 40, n. 3, p. 318-324, 2018.

MEIHY, José Carlos Sebe Bom; HOLANDA, Fabíola. História oral: como fazer, como pensar. São Paulo: Contexto, 2015

MENEZES, Rafael. Histórico, Brigada de Infantaria Pará-quedista. 2019. Disponível em: http://www.bdainfpqdt.eb.mil.br/historico.html. Acesso em: 9 maio 2019.

MEZZADRI, Fernando Marinho. As práticas esportivas nos clubes do Paraná: 1880-1920.

Conexões: Educação Física, Esporte e Saúde, v. 1, n. 3, p. 103-110, 1999.

MÜLLER, Edmilson Borges; ETO, Jorge. História Oral do Taekwondo em CuiabáMT: Os primeiros Mestres. Connection Line, n. 4, 2014. DOI: http://dx.doi. org/10.18312\%2Fconnectionline.v0i4.129

NAGADO, Alexandre; MATSUDA, Michel; GOES, Rodrigo de. Cultura Pop Japonesa histórias e curiosidades. 2011. Disponível em: http://nagado.blogspot.com/2011/12/culturapop-japonesa-e-book-gratuito.html . Acesso em: 5 maio 2019.

PASSOS, Alencar Daniella et al. As origens do vale-tudo na cidade de Curitiba-PR: memórias sobre identidade, masculinidade e violência. Movimento, v. 20, n. 3, p. 11531173, jul./set. 2014.

POLLAK, Michael. Memória, esquecimento, silêncio. Revista Estudos Históricos, v. 2, n. 3 , p 3-15, 1989.

POLLAK, Michael. Memória e identidade social. Revista Estudos Históricos, v. 5, n. 10, p. 200-215, 1992.

PORTELLI, Alessandro. História oral como arte da escuta. São Paulo: Letra e Voz, 2016.

PRADO, Rodrigo Cribari. A memória é uma ilha de edição: narrativas e significados sobre o início e a difusão do aikido no Brasil, 2014. (Mestrado em Educação Física) Departamento de Educação Física da Universidade Federal do Paraná, Curitiba. 2014.

REIS, Claudia; RODRIGUES, José de Almeida. Diamante: a história de Luiz Alves, lenda do Muay Thai e do MMA. São Paulo: Forma \& Conteúdo, 2018.

RIOS, Gleyson Batista. O processo de esportivização do Taekwondo. Pensar a Prática, v.8, n.1, p.37-54, jan./jun. 2005.

RUDNICK, Fernando. A vida de ermitão do mestre da luta. Curitiba, 24 jan. 2015.

Disponível em: https://www. dopovo.com.br/esportes/lutas/a-vida-de-ermitao-do-mestre-daluta-ej6yq4j6x0ojt5x52fgv5332m/. Acesso em: 4 maio 2019. 
SOUZA, Fernando. O adeus ao mestre Nélio Naja. 2018. Disponível em: https://www. tribunapr.com.br/blogs/direto-do-octogono/o-adeus-ao-mestre-nelio-naja/ Acesso em: 15 jul. 2019.

THOMPSON, Paul. A voz do passado: história oral. 3. ed. Rio de Janeiro: Paz e Terra,1992.

THOMPSON, Paul; ZHOURI, Andrea; LEITE PEREIRA, Ligia Maria. História oral e contemporaneidade. História oral, n. 5, p. 9-28, 2002.

TRALCI FILHO, Marcio Antonio. Tradição no Kung Fu: mestres brasileiros entre permanências e transformações. Movimento, v. 22, n. 1, p. 115-128, 2016.

VAIL, Peter. Modern" Muai Thai" Mythology. Crossroads: An Interdisciplinary Journal of Southeast Asian Studies, v. 12, n. 2, p. 75-95, 1998.

VAIL, Peter. Muay Thai: Inventing tradition for a national symbol. SOJOURN: Journal of Social Issues in Southeast Asia, v. 29, n. 3, p. 509-553, 2014. 